\title{
Osteocondrose de articulação fêmoro-tíbio-patelar em potro da raça Crioula
}

\author{
Stifle joint osteochondrosis in a Criollo foal
}

\author{
Andressa Bueno $^{\mathrm{I}^{*}}$ Jordana Beal $^{\mathrm{I}}$ Luiz Sergio Segala de Oliveira ${ }^{\mathrm{II}}$ \\ Flávio Desessards De La Corte ${ }^{\mathrm{II}}$
}

\begin{abstract}
Um potro da raça crioula, com dois anos de idade, foi encaminhado ao Hospital Veterinário da Universidade Federal de Santa Maria (UFSM) apresentando aumento de volume na região da patela esquerda e claudicação manifestada ao trote. Os exames físico e radiográfico identificaram a presença de uma lesão envolvendo o osso subcondral na tróclea lateral do fêmur, característica de uma osteocondrose. Trata-se do primeiro relato de osteocondrose em um potro da raça Crioula.
\end{abstract}

Palavras-chave: eqüino, articulação fêmoro-tíbio-patelar, osteocondrose.

\section{ABSTRACT}

A two-year-old Criollo foal was referred to the Veterinary Teaching Hospital of the UFSM presenting joint effusion on the left stifle joint. Physical and radiographic examination revealed the presence of osteochondreal fragmentation located at the lateral throclea ridge of the femur characterizing osteochondrosis in the stifle joint.

Key words: horse, stifle joint, osteochondrosis.

A osteocondrose é definida como um distúrbio na diferenciação celular normal no crescimento da cartilagem (HURTIG \& POOL, 1996; DOUGLAS, 2003). Uma definição mais genérica foi dada por SAVAGE (1998) e DOUGLAS (2003), que descreveram esta patologia como sendo uma falha no processo de ossificação endocondral.

HURTIG \& POOL (1996) e ROONEY (1998) acreditaram que animais jovens e atletas das raças Puro Sangue de Corrida (PSC), Quarto de Milha e Puro Sangue Árabe são acometidos com maior freqüência. Na maioria dos casos, esta condição é diagnosticada pela sua manifestação clínica, desde o nascimento até os dois anos de idade.

Classifica-se a osteocondrose em três categorias, sendo a primeira aquela que determina tanto sinais clínicos como radiográficos. A segunda apresenta sinais clínicos, sem alterações radiográficas visíveis, mas as lesões são passíveis de serem identificadas na artroscopia. Na terceira, as lesões se evidenciam no exame radiográfico, porém, o animal não apresenta sinais clínicos de aumento de líquido sinovial ou claudicação evidente. As osteocondroses das duas primeiras categorias são diagnosticadas com maior freqüência (McILWRAITH, 2002).

ROONEY (1998) descreve a etiologia da osteocondrose como complexa, mas acredita-se que seja uma combinação de fatores nutricionais, biomecânicos, genéticos, velocidade rápida de crescimento, conformação, traumatismo, ou ainda, uma manifestação isolada de apenas um desses fatores. A

\footnotetext{
IPrograma de Pós-graduação em Medicina Veterinária, Hospital Veterinário, Setor de Eqüinos, sala 439, Universidade Federal de Santa Maria (UFSM), Faixa de Camobi, km 9, 97105-900, Santa Maria, RS, Brasil. E-mail: abfisiovet@gmail.com. *Autor para correspondência.

IIDepartamento de Clínica Grandes Animais, UFSM, Santa Maria, RS
} 
osteocondrose apresenta-se com duas lesões características: a osteocondrite dissecante e os chamados cistos subcondrais, este último por sua aparência radiológica. Nos eqüinos, a osteocondrite dissecante manifesta-se mais comumente nas articulações fêmoropatelar (cristas trocleares medial e lateral do fêmur), tarsocrural (crista intermediária distal, tróclea medial e lateral do tarso e maléolo medial da tíbia), escápuloumeral (cavidade glenóide e cabeça do úmero) e articulações metacarpo/metatarsofalangeanas (crista sagital mediana e côndilos do terceiro osso metacarpo/metatarsiano) (DOUGLAS, 2003). Segundo McILWRAITH (2002), a articulação fêmoro-tíbio-patelar é o principal local de manifestação de lesão do tipo osteocondrite dissecante. Já os cistos subcondrais, de acordo com HURTIG \& POOL (1996), ocorrem em áreas que sustentam maior carga de peso, tais como o côndilo medial do fêmur, o côndilo medial do terceiro osso metacarpiano, a face medial das porções proximal e distal do rádio e a face proximal medial das falanges proximal e média.

Embora o tratamento conservativo seja uma alternativa para determinados casos de osteocondrose, dependendo do tipo de lesão e da articulação acometida, o tratamento cirúrgico por meio de uma artroscopia é a forma mais eficiente de tratamento (McILWRAITH, 2002; FOERNER, 2003). Nesse procedimento, o fragmento ósseo intra-articular é retirado e o osso subcondral é curetado. A indicação desse procedimento é mais segura quando a visualização do(s) fragmento(s) é possível no exame radiológico. Tanto para o tratamento conservativo como para o cirúrgico, a restrição parcial ou total de exercício é indispensável.

Um eqüino da raça Crioula, macho, dois anos de idade, peso corporal de 350 quilos, foi enviado ao Hospital Veterinário da UFSM para avaliação clínica por apresentar aumento de volume na região da articulação fêmoro-tíbio-patelar esquerda acompanhado de claudicação.

$\mathrm{Na}$ anamnese, realizada com o veterinário da propriedade de origem, constatou-se que o potro foi confinado na cocheira e recebeu por seis meses, aproximadamente, $6 \mathrm{~kg}$ de concentrado e $2 \mathrm{~kg}$ de feno de alfafa por dia, fracionados em três refeições. A ração fornecida era composta de $14 \%$ proteína bruta, 1,8\% extrato etéreo, $26 \%$ fibra, $13 \%$ de minerais além de 1,3\% de cálcio e $0,27 \%$ de fósforo, com uma concentração de energia digestível de 2,3Mcal kg-1.

Ao exame clínico, observou-se claudicação no membro posterior esquerdo, que se acentuava com o esforço físico. O teste de flexão da articulação fêmorotíbio-patelar por um minuto, que visa exacerbar a claudicação, foi positivo tanto no lado esquerdo (grau V) como no direito (grau III), conforme protocolo estabelecido (McILWRAITH, 2002). No membro posterior esquerdo, na altura da articulação fêmoro-tíbiopatelar, havia um aumento de volume, sem hiperestesia, de consistência mole e de mesma temperatura corpórea, característica de uma efusão sinovial. Na articulação do lado direito, havia um aumento de líquido sinovial mais discreto. Na avaliação das demais articulações, não foram observadas alterações.

Foram realizadas, radiografias nas incidências látero-medial $30^{\circ}$ obliqua e póstero-anterior, recomendadas para a avaliação da articulação em questão. O estudo radiológico revelou um fragmento ósseo subcondral na crista troclear lateral do fêmur, no membro pélvico esquerdo na projeção látero-medial oblíqua. O resultado dos exames físico e radiográfico apontou para o diagnóstico de osteocondrose da articulação fêmoro-tíbio-patelar esquerda.

O tratamento de eleição para este tipo de fragmentação do osso subcondral na tróclea lateral do fêmur é a remoção cirúrgica por meio da artroscopia. $\mathrm{O}$ potro foi submetido à uma cirurgia artroscópica na qual se removeu os fragmentos e o osso sub-condral foi curetado para estimular a cicatrização. Embora a cirurgia tenha sido satisfatória, o potro morreu dois meses após o procedimento devido a uma pleuro-pneumonia. No exame pós-mortem, observou-se o local onde a lesão foi curetada com preenchimento parcial do defeito no osso sub-condral pela fibrina. Lesões como as descritas aqui são muito mais freqüentes em cavalos da raça PSC do que em outras raças (FOERNER, 2003).

Embora a ocorrência dessa forma de doença ortopédica do desenvolvimento em potros seja multifatorial, a presença (isolada ou em combinação) de problemas nutricionais, biomecânicos (excesso de exercício), de circulação sangüínea, além de fatores genéticos, pode favorecer o aparecimento de osteocondrose (van WEEREN, 2006). O fator genético tem sido de interesse, uma vez que existem relatos da apresentação clínica ser mais característica em determinadas raças de cavalos e dentro de determinadas linhagens de uma mesma raça. Isso parece ser verdade quando se compara as raças de cavalos de salto e cavalos PSC (FOERNER, 2003). Determinar o impacto do fator genético em cavalos Crioulos somente será possível se um número significativo de casos for relatado e devidamente documentado no futuro.

No presente relato, é importante considerar o fator nutricional, já que o potro estava sendo preparado para um leilão e não estava sendo exercitado, situação muito freqüente nos estabelecimentos de criação comercial 
(ROONEY 1998; McILWRAITH, 2002). SAVAGE(1998) salientou a importância de se controlar a ingestão de carboidratos pelos animais em crescimento. Segundo a literatura, potros com essa idade devem ser alimentados com 2-2,5\% de seu peso corpóreo em volume de alimento diário (concentrado e volumoso) (ROONEY, 1996). Num estudo com potros, a alimentação com 130\% da necessidade de energia digestível em carboidratos resultou no aparecimento de lesões indicativas de osteocondrose (SAVAGE et al., 1993). Considerando que este potro Crioulo foi alimentado com $6 \mathrm{~kg}$ de concentrado por dia, durante quatro meses, e o teor de energia digestível no concentrado era de 2,3Mcal kg-1 (além do feno de alfafa consumido), isso corresponderia aproximadamente a um consumo diário de 13,8Mcal kg-1 de energia, estando bem acima dos 10,4Mcal kg-1 de ingestão máxima diária de energia digestível recomendados pelo fabricante. Dietas com base nos carboidratos solúveis, como a fornecida para este potro, tendem a maximizar as taxas de crescimento, o que pode interferir no equilíbrio de outros fatores nutricionais (necessidade de cálcio e fósforo) e hormonais (insulina, T3 e T4) (OTT, 1992).

Embora o prognóstico deste tipo de lesão na articulação fêmoro-tibio-patelar seja variável, as lesões restritas à tróclea lateral do fêmur geralmente tem chances favoráveis de recuperação (FOERNER, 2003).

No conhecimento dos autores, este é o primeiro caso documentado na literatura de osteocondrose em potros da raça Crioula. Estima-se um considerável aumento de casos diagnosticados em eqüinos desta raça, assim como o aparecimento de outras lesões nas demais articulações, em razão do crescente interesse pelas práticas esportivas e a intensificação do processo de criação.

Além de aspectos nutricionais, outros fatores deveriam ser analisados na criação do cavalo
Crioulo tais como a idade em que são preparados para a venda, idade de doma e intensidade dos exercícios para animais jovens.

\section{REFERÊNCIAS}

DOUGLAS, J. Pathogenesis of osteochondrosis. In: ROSS, M.W.; DYSON, S.J. Lameness in the horse. Philadelphia: Saunders, 2003. Cap.56, p.534-541.

FOERNER, J.J. Osteochondrosis in the horse. Journal of Equine Veterinary Science, v.23, n.4, p.142-145, 2003.

HURTIG, M.B.; POOL, R.R. Pathogenesis of equine osteochondrosis. In: McILWRAITH,C.W; TROTTER,G.W. Joint disease in the horse. Philadelphia: Saunders, 1996. Cap.20, p.335-358.

McILWRAITH, C.W. Diseases of joints, tendons, ligaments, and related structures. I n: STASHAK, T.S. Adam's lameness in horses. Philadelphia: Lippincott Williams \& Wilkins, 2002. Cap.7, p.543-556.

OTT, E.A. Nutritional factors in developmental orthopedic disease. In: __ Current therapy in equine medicine. Philadelphia: Saunders, 1992. Cap.17, p.720-724.

ROONEY, D.K. Clinical nutrition. In: REED, S.M.; BAYLY, W.M. Equine internal medicine. Philadelphia: Saunders, 1998. Cap. 5, p.232-234.

SAVAGE, C.J. Etiopathogenesis of osteochondrosis. In: WHITE, N.A.; MOORE, J.N. Current techniques in equine surgery and lameness. Philadelphia: Saunders, 1998. Cap.70, p.318- 322.

SAVAGE, C.J. et al. Effects of dietary energy and protein on induction of dyschondroplasia in foals. Equine Veterinary Journal, suppl.16, p.74-79, 1993

van WEEREN, P.R. Etiology, diagnosis and treatment of OC(D). Clinical Techniques in Equine Practice, v.5, n.4, p.248-258, 2006. 